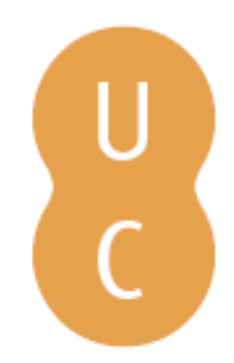

\title{
nommalina
}

\section{Encontros Ibéricos EDIBCIC, uma pequena história para uma ideia interessante}

Autor(es): $\quad$ Borges, Maria Manuel; Sanz-Casado, Elias

Publicado por: Imprensa da Universidade de Coimbra

URL

persistente: URI:http://hdl.handle.net/10316.2/31847

DOI: $\quad$ DOI:http://dx.doi.org/10.14195/978-989-26-0319-3_1

Accessed : $\quad$ 26-Apr-2023 11:51:48

A navegação consulta e descarregamento dos títulos inseridos nas Bibliotecas Digitais UC Digitalis, UC Pombalina e UC Impactum, pressupõem a aceitação plena e sem reservas dos Termos e Condições de Uso destas Bibliotecas Digitais, disponíveis em https://digitalis.uc.pt/pt-pt/termos.

Conforme exposto nos referidos Termos e Condições de Uso, o descarregamento de títulos de acesso restrito requer uma licença válida de autorização devendo o utilizador aceder ao(s) documento(s) a partir de um endereço de IP da instituição detentora da supramencionada licença.

Ao utilizador é apenas permitido o descarregamento para uso pessoal, pelo que o emprego do(s) título(s) descarregado(s) para outro fim, designadamente comercial, carece de autorização do respetivo autor ou editor da obra.

Na medida em que todas as obras da UC Digitalis se encontram protegidas pelo Código do Direito de Autor e Direitos Conexos e demais legislação aplicável, toda a cópia, parcial ou total, deste documento, nos casos em que é legalmente admitida, deverá conter ou fazer-se acompanhar por este aviso. 
Maria Manuel Borges

Elias Sanz Casado

Coordenação

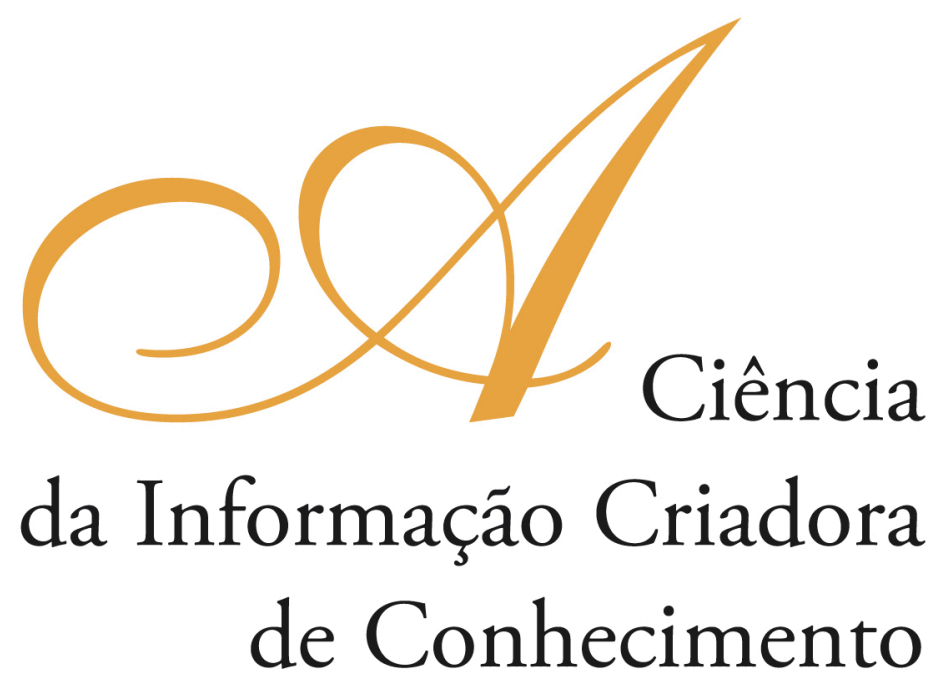

Vol. I

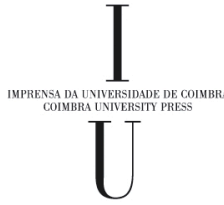

- COIMBRA 2009 


\section{ENCONTROS IBÉRICOS EDIBCIC, UMA PEQUENA HISTÓRIA PARA UMA IDEIA INTERESSANTE}

O Encontro EDIBCIC Ibérico que se realiza na Universidade de Coimbra constitui o quarto congresso regional da associação que tem lugar na Península Ibérica. Até agora, dois deles tinham tido lugar em Espanha e outros dois, com este último, em Portugal. A iniciativa para a realização destes encontros partiu da Asociación de Educación e Investigación en Ciencia de la Información de Iberoamérica y el Caribe (EDIBCIC), cujos coordenadores regionais quiseram dinamizar as actividades científicas espanhola e portuguesa, bem como fomentar a colaboração das áreas implicadas na Ciência da Informação. Outro dos objectivos implícitos na celebração destas jornadas era o de potenciar a presença dos investigadores e docentes destes dois países em todas as actividades da associaçáo ibero-americana.

A forma mais eficiente de melhorar o mundo é melhorar o ambiente que nos rodeia. Fazemos parte de um sistema complexo e invisível de vasos comunicantes que nos aproxima dos outros através de objectivos comuns que nos obrigam a procurar as soluções necessárias. Neste sentido, cremos que se somos capazes de fazer propostas atractivas de investigação e docência sobre os temas em que trabalhamos, seremos capazes de levar esse conhecimento ao resto dos países ibero-americanos que participam na associação com o objectivo de enriquecer e disseminar esse acervo comum.

A região ibero-americana constitui um espaço amplo e diverso, no qual partilhamos culturas, tradiçóes e interesses comuns em muitos temas de investigação. Tudo isso nos permite explorar novas iniciativas e colaborar para encontrar soluçôes que ampliem o nosso conhecimento. Com esta finalidade, decidimos criar um espaço de comunicação científica que nos permitisse trocar experiências de investigação e de docência realizados em universidades e centros de investigação portugueses e espanhóis. Decidimos que a cada dois anos, numa cidade de cada um dos países, se canalizará parte da actividade científica desenvolvida quotidianamente.

O primeiro encontro regional celebrou-se em 2003 na Faculdade de Biblioteconomia e Documentação da Universidade de Salamanca. A celebração deste encontro iniciou o processo de colaboração tendo-nos proposto manter ao longo do tempo a possibilidade de comunicação entre os docentes e investigadores das universidade e centros de informação dos dois países. Neste esforço, queremos reconhecer ao Professor José Antonio Frías a sua vontade pioneira para abrir e manter esta nova via de comunicação. Foi, sem 
dúvida, um dos protagonistas que trabalhou com maior afinco na consolidação deste encontro bianual no panorama da Ciência da Informação na regiấo Ibérica.

A este encontro assistiram alguns colegas portugueses e espanhóis que, durante um dia, procuraram e discutiram temas de interesse comum apesar dos distintos objectivos de investigação e docência de ambos os países. O compromisso firme e decidido de continuar com a ideia de manter estes encontros permitiu firmar o compromisso de nos reunirmos, dois anos depois, na cidade portuguesa do Porto.

A Professora Fernanda Ribeiro tomou a seu cargo a organização em 2005 do II Encontro da secção Ibérica do EDIBCIC na Faculdade de Letras da Universidade do Porto. Este encontro contou com a participação de um grupo maior de professores e investigadores dos dois países que trabalhavam na área da Ciência da Informação e que expuseram durante um dia os seus trabalhos de investigaçáo. Este segundo encontro permitiu-nos constatar que a ideia estava a germinar e que náo só era possível manter este tipo de reunióes, como também se despertava o interesse de outros profissionais e investigadores que se iam juntando à iniciativa.

Esta realidade confirmou-se no III Encontro na cidade espanhola de Salamanca na qual, e "Ao volante do Chevrolet pela estrada de Salamanca", título destas jornadas que se celebraram durante 3 dias, participou um grande número de profissionais e investigadores que já não se limitaram ao contexto espanhol ou português mas que incluíram diversos latino-americanos que vieram partilhar connosco os seus trabalhos de investigação. Pode-se dizer que este foi o ponto de encontro no qual se vislumbrou de maneira real que esta iniciativa tinha começado a ganhar vida dentro do panorama ibero-americano da Ciência da Informação. De algum modo, é um evento que já se esperava e que estava começando a formar parte do calendário de actividades dos investigadores neste campo do conhecimento. Outro facto significativo que, de maneira silenciosa, se ia constatando, e que constituía um dos objectivos originais destas realizaçôes, era a colaboração entre os investigadores dos dois países ibéricos. Neste sentido, este terceiro encontro coordenado pelos Professores José Antonio Frías e Fernanda Ribeiro estava conseguindo este objectivo.

Agora, e dois anos depois daquele evento, propomo-nos realizar convosco o IV Encontro na Faculdade de Letras da Universidade de Coimbra, tendo escolhido como tema "As relaçóes entre a Ciência da Informação e outras áreas do conhecimento: o papel da Ciência da Informação ao nível universitário". O motivo de eleger como temas tanto a transversalidade como o papel da Ciência da Informaçáo no âmbito universitário foi, o de reconhecer a importância que teve e tem o desenvolvimento dos conhecimentos provenientes de outras disciplinas que estiveram presentes nas suas origens e que ainda continuam a nutrir os conhecimentos que se geram na Ciência da Informação; o outro aspecto que queremos realçar é o papel que joga esta disciplina no contexto universitário. Neste sentido, cremos que é cada vez maior a sua relevância e que vale a pena analisá-lo. É importante constatar como se está a produzir uma viagem de ida e volta que faz com que os conhecimentos gerados na Ciência da Informação comecem a introduzir-se e, mediante um processo de capilaridade com as outras disciplinas, a formar parte do tecido universitário.

Este quarto encontro regional do EDIBCIC continuou a tradição anterior e saltou as fronteiras da península Ibérica, recebendo propostas de participação de investigadores e profissionais do âmbito da Ciência da Informaçáo de um grande número de países 
ibero-americanos. No total, o número de propostas que recebemos foi quase de 200. Com tal expressáo, podemos afirmar que a ideia primitiva se consolidou, que conseguimos todos participar nos objectivos de um colectivo, que, como comentávamos no início, constituímos um espaço amplo e diverso mas no qual partilhamos cultura, tradiçóes e interesses comuns em muitos temas, entre eles os de investigação e de docência.

Não temos dúvidas de que os contributos que se façam neste encontro e que estarão divididos em subtemas como o estatuto epistemológico da Ciência da Informação, a Ciência da Informação e a formação no contexto ibérico sob o prisma de Bolonha, as perspectivas de investigação, e, finalmente, o diálogo entre a formação e a sociedade, passarão a engrossar esse conhecimento comum e que já partilhamos no EDIBCIC.

Finalmente, resta-nos agradecer a todos os que participaram na organizaçáo do Encontro o seu generoso esforço que esperamos se veja recompensado pelos resultados científicos e profissionais que se conseguirão.

Maria Manuel Borges (Universidade de Coimbra) Elias Sanz-Casado (Universidade Carlos III de Madrid)

Coordenadores cientificos do IV Encontro

Coimbra, Novembro de 2009 